\title{
Numerical Derivation of Pressure-Impulse Diagrams for Prediction of RC Column Damage to Blast Loads
}

\author{
Yanchao Shi, ${ }^{1,2}$, Hong $\mathrm{Hao}^{1 *}$ and Zhong-Xian $\mathrm{Li}^{2}$ \\ ${ }^{1}$ School of Civil \& Resource Engineering, the University of Western Australia, \\ 35 Stirling Highway, Crawley WA 6009, Australia. \\ ${ }^{2}$ School of Civil Engineering, Tianjin University, Tianjin 300072, China
}

\begin{abstract}
Pressure-impulse (P-I) diagrams are commonly used in the preliminary design or assessment of protective structures to establish safe response limits for given blast-loading scenarios. Current practice in generating the pressure-impulse diagram for structure components is primarily based on the simplified SDOF model. The damage criterion is usually defined in terms of deformation or displacement response. Under blast loads, structures usually respond at their local modes, the equivalent SDOF system derived using the fundamental structure response mode might not be suitable. Moreover, structure is often damaged owing to brittle shear failure. In this case, the deformation based damage criterion might not be able to give an accurate indication of local damage of a structural component. In this paper, a new damage criterion for RC column is defined based on the residual axial load carrying capacity. A numerical method to generate pressure-impulse diagram for RC column is proposed. Parametric studies are carried out to investigate the effects of column dimension, concrete strength, longitudinal and transverse reinforcement ratio on the pressure-impulse diagram. Based on the numerical results, analytical formulae to predict the pressure-impulse diagram for RC column are derived. A case study shows that the proposed analytical formulae can be easily used to generate pressure-impulse diagram for RC columns accurately. The results are also compared with those obtained from the SDOF approach. It is shown that the proposed method gives better prediction of pressure-impulse diagram than the SDOF approach.
\end{abstract}

Keywords: RC Column, Pressure-impulse diagrams, damage criterion, numerical derivation, analytical formulae

\footnotetext{
* Corresponding author. Tel: +61 86488 1825; Fax: +61 864881018

E-mail: hao@civil.uwa.edu.au (Hong Hao)
} 


\section{Introduction}

A pressure-impulse diagram is an iso-damage curve (i.e., each combination of pressure and impulse produces the same damage in a structure component) for a particular structural component loaded with a particular loading history (e.g., blast load). It was first developed in the study of houses damaged by bombs dropped on UK in the Second World War [1, 2], and then was derived usually from the analysis of an elastic SDOF model [2, 3]. These iso-damage pressure-impulse diagrams have been also applied to predict structural damage [4, 5], as well as blast-induced human injuries [2, 4-6].

Fig. 1 shows the primary features that define a pressure-impulse diagram. The two asymptotes, one for pressure and one for impulse, define limiting values for each parameter. Thus, loads with very short duration (relative to the structure's natural frequency) are called impulsive loading and the structure response is sensitive only to the associated impulse and not to the peak pressure. This forms a vertical line that defines the minimum impulse required to reach a particular level of damage, which the curve approaches asymptotically at high pressures. Conversely, as the load duration becomes longer than the natural frequency, the load is termed quasi-static loading and the response becomes insensitive to impulse but very sensitive to peak pressure. The horizontal asymptote thus represents the minimum level of peak pressure required to reach that particular damage.

As seen, the pressure-impulse curve itself divides the pressure-impulse space into two regions: that above and to the right of the curve where the damage level of the structure component is exceeded, and that below and to the left where the level is lower. The pressure-impulse diagrams usually contain a group of pressure-impulse curves with different degrees of damage. These curves divide the pressure-impulse space into several regions, each corresponding to a particular level of damage, and the curves themselves represent the boundaries between different damage levels, such as low damage, medium damage and high damage.

Great progress on developing P-I diagrams of structure components has been made in the recent years. Li and Meng $[7,8]$ have studied the pulse loading shape effects on the pressure-impulse diagram based on the maximum deflection damage criterion and elastic single degree of freedom (SDOF) model. It was found that there is a noticeable loading shape influence on the pressure-impulse diagram when both 
peak pressure and impulse are important for dynamic structural response. Fallah and Louca [9] have derived pressure-impulse diagram from analyzing SDOF systems with elastic-plastic-hardening and elastic-plastic softening under blast loads. Recently, a few researchers have also reported their attempt to use pressure-impulse diagram to evaluate the damage levels of various structural members [10-13]. However, the pressure-impulse diagram generated by the current approaches may not give reliable prediction of structure component damage because of the following reasons:

(1) Most of the previous studies are based on the SDOF model. As is well known, a structure responds to blast load primarily at their local modes. The local modes of the structure may govern the structure damage, especially when the blast load is of short duration [14]. The use of SDOF model may not be suitable for structure damage analysis to blast loads. Moreover, the SDOF model is not suitable to model multi-failure modes of a structural component either. For example, a column might be damaged owing to shear failure initially and subsequently by flexural failure to collapse. Therefore, pressureimpulse diagram generated from analysis of a SDOF system may not give accurate prediction of structural component damage.

(2) The deformation based damage criterion may not be appropriate for the evaluation of local damage of a structural component subjected to blast loads, especially when the damage is caused primarily by shear failure.

On the other hand, using experiment-based methods to generate the pressure-impulse diagram for structural components is expensive. In order to get enough data to form a valid pressure-impulse diagram, a broad spectrum of loading and structural parameters should be considered.

The objective of the present work is to derive formulae for generating the pressure-impulse diagram for RC columns. The numerical models of a series of columns are established using software LS-DYNA. In the model, both the strain rate effect of the materials and the bond slip between steel bar and concrete are considered. A new damage criterion for the RC column under blast loads is proposed to estimate damage levels. Based on the numerical results and the damage criterion, a simplified numerical method to generate the pressure-impulse of RC columns is proposed. Parameters that may affect the pressureimpulse diagram of a RC column are considered in the present study, they are column dimension, concrete strength, longitudinal and transverse reinforcement ratio. Analytical formulae to predict the 
pressure-impulse diagram for RC columns are also derived based on the numerical results. The results obtained from the proposed analytical formulae are compared with those based on the SDOF model. It is shown that the proposed method gives better prediction of pressure-impulse diagram of RC columns than that obtained from the SDOF approach.

\section{Numerical analysis of RC column damage to blast loads}

Structure response and/or damage to blast loads are normally obtained using the following three methods: (1) theoretical analysis (2) explosion test and (3) numerical analysis. Most theoretical studies on the dynamic behaviour of structures subjected to blast loads have been mainly dealt with the large plastic deformation of simple structures such as beams and unstiffened plates. Due to the rigid- plastic material idealization and the negligence of strain hardening and strain rate effects in the analysis, the theoretical prediction of structure response and damage to blast loads may not very accurately reflect the true behaviour of a structure. Explosion test is a good way to study the structure response to blast loads; however, it is not only very expensive but also not possible in many cases due to the safety and environmental consideration. With the development of computer technology and computational mechanics, it becomes possible to reliably predict structure response and/or damage to blast loads with numerical techniques. Therefore, in the present study, the hydrocode LS-DYNA is utilized to analyse the RC column damage to blast loads.

\subsection{Elements and boundaries}

The RC column studied herein is shown in Fig. 2. In Fig. 2(a), $b$ is the column width, facing the blast loads; $h$ is column depth and $a$ is the cover depth. In Fig. 2(b), $H$ is the clear height of the RC column and $s$ is the tie spacing.

Solid elements of $25 \mathrm{~mm}$ cube with a single integration point were used to model the concrete, and $25 \mathrm{~mm}$ long beam elements were used for the vertical reinforcement bars and the ties. Numerical convergence study shows that further decrease of the mesh size only has little effect on the numerical results but leads to a much longer calculation time. Therefore, a mesh size of $25 \mathrm{~mm}$ is used in the study.

In order to provide higher fidelity for the column constraints, a footing and a head are included in the numerical model, as shown in Fig. 2. The outer vertical face of the footing and head were constrained 
against horizontal motions (i.e., in the $\mathrm{x}$ - and $\mathrm{y}$ - direction) and the bottom face of the footing is constrained against vertical motion (i.e., in z- direction).

In numerical simulations, the idealized triangular blast load is uniformly applied to the front face of the RC column. Each blast load represents a combination of a peak pressure and an impulse. It should be noted that the actual blast load may vary along the column height and the blast pressure time history is usually not triangular $[8,15]$. However, the present simplification of the blast load shape and distribution is consistent with the specifications given in the design code [16]. When the explosion center is very near the column, this simplification may over predict the column damage levels.

\subsection{Material model}

The material model CONCRETE DAMAGE REL3 (MAT_72_REL3) available in LS-DYNA is utilized in the present study to model concrete. A number of material models in LS-DYNA can be used to model concrete, such as BRITTLE DAMAGE (MAT_96), JOHNSON HOLMQUIST CONCRETE (MAT_111) and CSCM CONCRETE (MAT_159) [17]. However, it is well known that the numerical results are very sensitive to the material properties, thus the ability to define the material model accurately is one of the most important issues in the numerical simulation. The advantage of the model used is that it is a concrete model based on one user input parameter, i.e., the unconfined compressive strength. Since the unconfined compressive strength can be easily derived from simple experiments, the present concrete model is very useful when the information of the concrete is very limited. Previous studies have shown that the model provides a robust representation of complex concrete laboratory response [18] and can be used in the structure response analysis to blast loads [19].

Material model PLASTIC_KINEMATIC (MAT_003) is used to model steel. It is an elastic-plastic material model with strain rate effect. The parameters of this material model are defined based on the quasi-static testing results of D500BT type 1 rebar steel with 16mm and nominal yield stress $500 \mathrm{MPa}$ done by Hansson [20]. They are shown in Table 1.

\subsection{Strain rate effect}

When the RC structures are subjected to blast loads, both concrete and steel may respond at very high strain rates in the order of $10 \mathrm{~s}^{-1}$ to $1000 \mathrm{~s}^{-1}$ or even higher. At these high strain rates, the apparent strength of these materials can increase significantly, by more than 50 percent for the reinforcing steel, by 
more than 100 percent for concrete in compression, and by more than 600 percent for concrete in tension [21]. Therefore, the strain rate effect for concrete and steel needs be considered for a reliable simulation of structural response to blast loads.

The effect of strain rate on the concrete and steel strength is typically represented by a parameter, namely the dynamic increase factor (DIF). It is a ratio of the dynamic-to-static strength versus strain rate. Usually, the strain rate effect is also response time history dependent. However, in practice it is always assumed to depend on the strain rate only.

Many empirical relations are available in the literature to estimate strain rate effect on concrete material properties. In particular, the code by the Comite Euro-international du Beton (CEB) [21, 22] recommended various values of the dynamic increase factor (DIF) for compressive and tensile strengths under high rates of loading based on test results. In tension, the dynamic increase factor (DIF) of the tensile strength is given by the following equations,

$$
\begin{array}{lll}
\text { TDIF }=\frac{f_{t d}}{f_{t s}}=\left(\frac{\dot{\varepsilon}_{d}}{\dot{\varepsilon}_{t s}}\right)^{1.016 \delta} & \text { for } & \dot{\varepsilon}_{d} \leq 30 \mathrm{~s}^{-1} \\
\text { TDIF }=\frac{f_{t d}}{f_{t s}}=\beta\left(\frac{\dot{\varepsilon}_{d}}{\dot{\varepsilon}_{t s}}\right)^{1 / 3} & \text { for } & \dot{\varepsilon}_{d}>30 \mathrm{~s}^{-1}
\end{array}
$$

where $f_{t d}$ is the dynamic tensile strength at the strain rate $\dot{\varepsilon}_{d}, f_{t s}$ is the static tensile strength at the strain rate $\dot{\varepsilon}_{t s}\left(\dot{\varepsilon}_{t s}=3 \times 10^{-6} s^{-1}\right)$, and $\log \beta=7.11 \delta-2.33$, in which $\delta=1 /\left(10+6 f_{c}^{\prime} / f_{c o}^{\prime}\right)$, $f_{c o}^{\prime}=10 \mathrm{MPa}$, and $f_{c}^{\prime}$ is static uniaxial compressive strength in MPa. In compression the empirical formulae are given as

$$
\begin{array}{lll}
C D I F=\frac{f_{c d}}{f_{c s}}=\left(\frac{\dot{\varepsilon}_{d}}{\dot{\varepsilon}_{c s}}\right)^{1.026 \alpha} & \text { for } & \dot{\varepsilon}_{d} \leq 30 \mathrm{~s}^{-1} \\
C D I F=\frac{f_{c d}}{f_{c s}}=\gamma\left(\dot{\varepsilon}_{d}\right)^{1 / 3} & \text { for } & \dot{\varepsilon}_{d}>30 \mathrm{~s}^{-1}
\end{array}
$$

where $f_{c d}$ is the dynamic compressive strength at the strain rate $\dot{\varepsilon}_{d}, \dot{\varepsilon}_{c s}=30 \times 10^{-6} \mathrm{~s}^{-1}$, $\log \gamma=6.156 \alpha-0.49, \alpha=\left(5+3 f_{c u} / 4\right)^{-1}, f_{c s}$ is the static compressive strength, and $f_{c u}$ is the static cube compressive strength in MPa. 
For steel, the strain rate effect based on K\&C model [23] is utilized. The dynamic increase factor (DIF) is given as,

$$
\begin{gathered}
D I F=\left(\frac{\dot{\varepsilon}}{10^{-4}}\right)^{\alpha} \\
\alpha=0.074-0.040 \frac{f_{y}}{414}
\end{gathered}
$$

where $\dot{\varepsilon}$ is the strain rate of the steel bar in $\mathrm{s}^{-1}$ and $f_{y}$ is the steel bar yield strength in MPa. This formulation is valid for steel bars with yield stress between 290 and 710 MPa and for strain rate between $10^{-4} \mathrm{~s}^{-1}$ and $225 \mathrm{~s}^{-1}[23]$.

\subsection{Bond slip}

The stress transfer behavior between reinforcing steel and surrounding concrete through bond and slip plays an important role in the response of RC structures [24, 25], especially in their dynamic response. Therefore, the bond slip between steel bar and concrete is considered herein.

One-dimensional slide line, which is intended for use in modeling bond slip in LS-DYNA, is used to model the bond slip between steel bar and concrete. In this bond slip model, the slave node of a string of beam elements, modeling the steel bar, is forced to slide along a master line of nodes embedded in the solid mesh, which models the concrete matrix. This kinematics constraint is applied using a penalty function approach; fictitious springs are inserted between slave nodes and their projections over the master lines. These springs produce internal forces proportional to the distance between slave nodes and master lines after the steel bar debonds [17, 26].

The bond strength between concrete and steel bar is one of the most important parameters to define the one-dimensional slide line. It has been investigated by pull out experiments and was found that the bond stress due to static friction and chemical adhesion between the concrete and steel bar is 6.6 MPa for quasi-static loading, 18.0 MPa for dynamic loading and 22.0 MPa for impact loading [26]. As to the case of RC column subjected to blast loads, the bond strain between the steel bar and the surrounding concrete may take a little longer time to reach the maximum than the direct pull out test. Therefore, 18.0 MPa is used as the maximum bond strength between concrete and steel bar in the present study. 


\subsection{Validation of the numerical model}

In order to validate the accuracy and reliability of the aforementioned numerical model, a numerical analysis of a quarter-scale RC column under blast loads was performed and its results were compared with the test and numerical results reported by Woodson and Baylot [27, 28].

A series of experiments with five different two-story, quarter-scale RC structures have been conducted by Woodson and Baylot $[27,28]$ to investigate the response of the exterior column to blast loads. Only the first-floor center column in experiment No. 2 is analyzed herein. Fig. 3 (a) shows the sketch of the configuration of experiment No. 2. The four corner columns of each model were not considered to be testing columns; thus, they were oversized and over-reinforced. The two center columns (common to both bays) served as the test columns. In this paper, the studied column is the center column at the ground floor, as indicated in the figure. $7.10 \mathrm{~kg}$ of C-4 at a standoff (center of charge to the face of column) of 1.07 m was used to generate the blast environment. The details of the geometry and material properties of the studied column (column C1) and the blast environment are given in Table 2-Table 4.

Two 3D numerical models for the quarter-scale RC column are set up in LS-DYNA, one includes the bond slip between steel bar and concrete and the other assumes perfect bond between reinforcement and concrete. The numerical analysis of these two columns under the same blast loads as in the experiment is conducted. The blast loads acting on the column front face is obtained using software AUTODYN [29]. The peak pressure and impulse of the blast load are $6100 \mathrm{kPa}$ and $1010 \mathrm{kPa} \bullet \mathrm{ms}$, respectively. These are smaller than the measured blast load acting on the column front surface in the test (an average value of $7000 \mathrm{kPa}$ for peak pressure and $1100 \mathrm{kPa} \cdot \mathrm{ms}$ for impulse). This is because the mesh size used in AUTODYN to simulate blast pressure wave propagation is $10 \mathrm{~mm}$. Reduce the mesh size will result in better predictions of the blast loads on columns, but will cause computer overflow owing to the software and computer limitations. Detail discussion of the simulation of blast pressure wave propagation is out of the scope of this paper. As the measured pressure time history is not available, besides the peak pressure and impulse, the numerically simulated pressure time history is approximately used in this study.

The comparison of the calculated and measured deflection time histories at the middle of the column is shown in Fig. 3 (b). From this figure one can find that: (1) the present numerical predictions are better than the analytical results obtained by Woodson and Baylot. This might be due to the better definition of 
the material properties for both concrete and steel in the present model; (2) considering the bond slip between steel bar and concrete yields better prediction. Therefore, the bond slip effect is modelled in the following simulations in this study; and (3) the peak deflection obtained from the present analysis is a little smaller and peak response occurs at a delayed time instant than the measured one, but the residual deflections are almost the same. This is because the simulated blast load is smaller than the actual load acting on the column, as discussed above. Considering the relatively smaller blast load used in the calculation, the numerical model gives reliable predictions of the reinforced concrete column response to blast loads.

\subsection{Possible damage modes}

Two damage modes have been observed during the numerical simulation of RC column damage to blast loads. One is shear damage, and the other is flexural damage. Sometimes the failure of the column could be a combination of the above two modes. The typical results of these three damage modes derived from numerical simulation are shown in Fig. 4.

Numerical results also show that when the column is subjected to impulsive blast load, i.e. in the impulsive loading region, it is inclined to be damaged by shear. In the quasi-static region, however, the column is likely damaged by flexural mode. And in the region of dynamic loading, the failure of the column might be a combination of shear and flexural damage. This is because, in the impulsive loading region, the blast load is usually of big peak and short duration, in such a short time, shear stress grows quickly to a big value but the flexural deflection has no time to develop. Therefore, shear damage is likely to happen. In the quasi-static region, on the other hand, the blast load is of small peak but long duration. In this case, the maximum shear stress in the column is small but the flexural deflection could develop to a large value, which is likely to lead to a flexural damage. However, it should be mentioned that these are some general observations only. The damage modes also depend on the column properties.

\section{Pressure-impulse diagram for RC columns}

In this section, a new damage criterion is defined, and then based on the proposed damage criterion and numerical observations,, a simplified numerical method to generate the pressure-impulse diagram for a RC column is proposed and explained. 


\subsection{Damage criterion}

The following principles are considered when defining the damage criterion:

(1) It should be suitable for evaluation of RC column damage from all possible damage modes;

(2) It should be related to the column global properties, besides column material damage; and

(3) It should be easy to use in assessing column conditions and easily obtained from numerical or experiment tests.

None of the commonly used damage criteria, such as the permanent deflection at the middle of column, material modulus reduction, the maximum stress or the maximum strain, satisfy the above principles. Considering that columns are all primarily designed to carry the axial loads (horizontal loads are mainly transferred to the rigid floor and the shear wall); the RC column axial load carrying capacity degradation is proposed in this study to quantify column damage.

The axial load carrying capacity degradation is suitable for evaluating the RC column shear damage and flexural damage, as well as local damage. It is also a parameter that is directly related to the global properties and functionality of the RC column, and can be easily obtained from the numerical simulation or experiment tests. .

The axial load carrying capacity of an undamaged RC column depends on the longitudinal reinforcement and concrete. According to MacGregor [30] and ACI Code the following equation is used to assess the maximum axial load carrying capacity of an undamaged RC column:

$$
P_{N}=0.85 f_{c}^{\prime}\left(A_{G}-A_{S}\right)+f_{y} A_{S}
$$

Where $f_{c}^{\prime}=$ compressive strength of concrete, $f_{y}=$ yield strength of the longitudinal reinforcement, $A_{G}=$ gross area of the column cross section, $A_{S}=$ the area of the longitudinal reinforcement.

The damage index $\mathrm{D}$ is defined as:

$$
D=1-\frac{P_{N_{-} \text {residual }}^{\prime}}{P_{N_{-} \text {design }}^{\prime}}
$$


where $P_{N_{\text {_residual }}}^{\prime}$ is the residual axial load carrying capacity of the damaged RC column. It can be obtained from the numerical simulation as will be described in the next section or test. $P_{N_{-}}^{\prime}$ design is the design axial load carrying capacity of the undamaged RC column, which can be derived using Eq. (7).

The degrees of damage are defined in this study as follows:

$$
\begin{aligned}
& \mathrm{D}=(0 \sim 0.2) \text { low damage } \\
& \mathrm{D}=(0.2 \sim 0.5) \text { medium damage } \\
& \mathrm{D}=(0.5 \sim 0.8) \text { high damage } \\
& \mathrm{D}=(0.8 \sim 1) \text { collapse }
\end{aligned}
$$

This definition is subjective, but the physical meaning is clear.

\subsection{Simplified numerical method to generate pressure-impulse diagram}

In order to generate pressure-impulse diagram for RC columns, a series of numerical simulations are carried out to obtain RC column damages at various degrees. The blast loads, i.e., peak pressure and impulse, corresponding to the RC column damages, will be plotted in the pressure-impulse space together with the damage level (see Fig. 5 (a)). Finally the pressure-impulse curves, which are the boundary lines between different damage levels, could be obtained using the curve-fitting method.

The degrees of damage of the RC column under a certain blast load can be obtained through the following procedure:

Stage 1: In this initial stage, an axial force is applied initially to the column prior to the blast loads to simulate the stress state present in the column due to the axial loads. This stage takes $50 \mathrm{~ms}$, because in explicit dynamic analysis, this axial force must be applied gradually. The initial dead weight applied to the column is $20 \%$ of design axial load carrying capacity in this study. This represents a typical ground floor column in a low to medium rise building.

Stage 2: Blast loads are applied over the front face of the column. The dynamic analysis for computing the column response to the blast load needs to be executed for a sufficiently long period of time to capture the complete blast response. Since it is extremely time consuming to carry out the 
simulation until the column reaches the complete still position. In this stage, the simulation is stopped when the velocities at all the nodes are sufficiently small, i.e., less than $0.1 \mathrm{~m} / \mathrm{s}$.

Stage 3: At the beginning of this loading stage, the velocity of the model needs be reset to zero. Then axial load is applied to the column again to obtain the load-deflection curve and the residual axial load carrying capacity of the post-blast column. This is accomplished by applying a gradually increasing downward vertical displacement at the column top. It should be noted that resetting the velocity to zero at the beginning of this stage would introduce some numerical error. However, since the initial velocities at all the nodes of the column are sufficiently small, this error could be ignored.

Stage 4: Estimate the damage index from the numerical results.

Fig. 5 (a) shows the pressure-impulse diagram of RC column C2 derived from the curve-fitting method. The configuration of column C2 is given in Table 2. It should be mentioned here that since it is very difficult to obtain the exact critical damage degree for damage boundaries, i.e., $\mathrm{D}=0.2$, or $\mathrm{D}=0.5$, etc., the numerical data obtained in a range is used for the curve fitting. For example, all the data around $\mathrm{D}=0.2$ is used to get the curve for $\mathrm{D}=0.2$. The range of the data around the aimed damage degree is decided by trial and error, so that the derived pressure-impulse curves are the approximate upper bounds of the simulated data for the respective damage levels, as shown in Fig 5 (a).

A careful examination of the fitted pressure-impulse curves finds that they can be expressed analytically as:

$$
\left(P-P_{0}\right)\left(I-I_{0}\right)=A\left(P_{0} / 2+I_{0} / 2\right)^{\beta}
$$

where $P_{0}$ is the pressure asymptote for damage degree $D$. In this paper, $D$ is taken as $0.2,0.5$ and 0.8 , respectively. $I_{0}$ is the impulsive asymptote for damage degree $D$; $A$ and $\beta$ are constants, which are related to the column configuration and degree of damage. $P_{0}, I_{0}, A$ and $\beta$ of column $\mathrm{C} 2$ for the three pressureimpulse curves are given in Table 5. From this table we can see that $A$ and $\beta$ are almost the same for different pressure-impulse curves, i.e., $A \approx 12, \beta \approx 1.5$, so they can be assumed to be independent of the degree of damage. Therefore, Eq. (9) can be expressed as:

$$
\left(P-P_{0}\right)\left(I-I_{0}\right)=12\left(P_{0} / 2+I_{0} / 2\right)^{1.5}
$$

Fig. 5 (b) shows the pressure-impulse curves derived according to Eq. (10) with the numerical data. It shows that the pressure-impulse curves obtained according to Eq. (10) matches reasonably well with the 
numerical data. Fig. 5 (c).compares the fitted curves given in Fig. 5 (a).and Fig. 5 (b). As shown, Eq. (10) well represents the pressure-impulse curves of a RC column.

Further study is conducted to investigate whether Eq. (10) can be used for other RC columns. The same procedure is used to estimate damage degrees of RC column C3 under different blast loads. The configuration of column C3 is given in Table 2. The damage levels with respect to peak pressure and impulse are plotted in the pressure-impulse space in Fig. 6. The best-fitted pressure-impulse curves according to Eq. (10) are also plotted in Fig. 6. It shows that the pressure-impulse curves almost fit the boundary lines between different damage levels. This demonstrates that Eq. (10) can be used to model pressure -impulse curves for all RC columns.

Since using Eq. (10) to model a pressure-impulse curve substantially reduces the number of data points required to fit a reliable pressure-impulse curve, Eq. (10) is used in this paper to model the variations of pressure-impulse curves.

According to the previous discussions, the procedure to generate a pressure-impulse diagram for a RC column can be simplified to the following two steps:

(1) Perform numerical simulations to obtain the damage degrees for the RC column under blast loads in two ranges. One is in the impulsive loading range, and the other is in the quasi-static loading range. The results (damage level) together with the blast peak pressure and impulse are then plotted in the pressure-impulse space (see Fig. 7).

(2) Using Eq. (10) as the regression model, obtain the best-fitted pressure-impulse curves, which are the boundaries between different damage levels, as seen in Fig. 7.

\section{Parametric studies}

Using the proposed simplified numerical method, further studies are carried out to investigate the effect of different parameters on the pressure-impulse diagram of RC columns. The parameters investigated within the scope of this study are column dimension, concrete strength, amount of longitudinal reinforcement and amount of transverse reinforcement. Table 6 summarizes the range of the parameters considered in the study. 


\subsection{Column depth, h}

In order to investigate the effect of column depth on the RC column pressure-impulse diagram, the pressure-impulse diagrams of three RC columns with different column depth, i.e. $400 \mathrm{~mm}, 600 \mathrm{~mm}$ and $800 \mathrm{~mm}$ are derived using the proposed method. They are shown in Fig. 8. For comparison purpose, the pressure asymptotes and impulsive asymptotes of the pressure-impulse curves shown in Fig. 8 are listed in Table 7. From Fig. 8 and Table 7 one can see that when the column depth increases, both the pressure and impulsive asymptotes of the pressure-impulse curves increase. This means that a column with a larger depth can resist a bigger quasi-static blast load, as well as a bigger impulsive blast load. This is expected because increasing the column depth means more concrete area and larger cross section modulus, which will increase both the shear strength and bending strength of the column.

\subsection{Column height, $\mathrm{H}$}

The pressure-impulse diagrams for another three columns with different column height are derived to examine the column height effect. Table 8 shows the pressure asymptotes and impulsive asymptotes of the pressure-impulse curves, from which one can see that both the pressure asymptote and impulsive asymptote decrease with the column height. This result is consistent with the fact that when the column is higher, it is easier to be damaged by the same blast load, especially when the blast load is quasi-static. However, it should be noted that this result is obtained based on the assumption of uniformly distributed blast loads on the column. If blast load is not uniformly distributed such as in a case where the explosive is very near the column base, this observation might not be true.

\subsection{Column width, $b$}

The results of the analyses carried out for different column width (see Table 9 ) show that increasing the column width will only slightly increase the pressure asymptote but decrease the impulsive asymptote of the pressure-impulse curve. This is because increasing the column width will increase the blast loads acting on the column, although the shear strength and the bending strength of the column will also increase. This observation indicates that increasing column width is not as effective as increasing column depth on blast load resistance capacity of the column. Again, it should be noted that this observation is made based on the assumption of uniformly distributed blast load on column front surface. 


\subsection{Concrete strength, $f_{c}$}

Columns with concrete strength of 30, 40 and 50 MPa were analysed to generate the corresponding pressure-impulse diagrams. The pressure asymptotes and impulsive asymptotes of the pressure-impulse curves are given in Table 10. It shows that increasing the concrete strength will increase both the pressure and the impulsive asymptote of the pressure-impulse curve. This can be explained by the fact that the concrete strength contributes to both the shear and bending strength of the column.

\subsection{Transverse reinforcement ratio, $\rho_{\mathrm{s}}$}

The effect of transverse reinforcement ratio is investigated by comparing the pressure-impulse diagrams for RC columns with different transverse reinforcement ratio $\rho_{\mathrm{s}}$, i.e. the volumetric ratio of transverse reinforcement. The results (Table 11) reveal that when the transverse reinforcement ratio is increased, the impulsive asymptote of the pressure-impulse curve will significantly increase and the pressure asymptote will also increase. This is because increasing the transverse reinforcement ratio will greatly increase the column's shear strength. It will also improve the column's bending strength.

\subsection{Longitudinal reinforcement ratio, $\rho$}

The comparisons of the pressure asymptotes and impulsive asymptotes of pressure-impulse curves for RC columns with different longitudinal reinforcement ratios are given in Table 12. It indicates that with the increase of the longitudinal reinforcement ratio, the pressure asymptote of the pressure-impulse curve will increase, as expected. However, the impulsive asymptote remains almost unchanged. This is because increasing the longitudinal reinforcement ratio can significantly increase the bending strength of the RC column, but has little contribution to the shear strength.

It should be mentioned that if a RC column is not designed properly, i.e. with a large longitudinal reinforcement ratio but insufficient transverse reinforcement, the pressure asymptotes of the pressureimpulse curves might decrease with the increase of the longitudinal reinforcement ratio. This is because of the poor confinement to the longitudinal steel bar and core concrete. 


\section{Analytical formulae to generate pressure-impulse diagram}

\subsection{Derivations of the analytical formulae}

Based on the numerical results, analytical formulae were developed to predict the pressure asymptotes and impulsive asymptotes for the pressure-impulse curves when the degree of damage equals $0.2,0.5$ and 0.8 , which are the critical value between different damage levels defined in this study.

Using the least squares fitting method, the pressure asymptote $P_{0}(D)$ and impulsive asymptote $I_{0}(D)$ are derived from numerical simulation data as a function of transverse reinforcement ratio $\rho_{s}$, longitudinal reinforcement ratio $\rho$, concrete strength $f_{c}^{\prime}$, column height $H$, column depth $h$ and column width $b$. They are:

$$
\begin{aligned}
& \left\{\begin{aligned}
P_{0}(0.2)= & 1000\left[0.007 \exp \left(\frac{\rho_{s}}{0.01}\right)+0.069\left(\frac{\rho}{0.01}\right)+0.034 \exp \left(\frac{f_{c}^{\prime}}{30}\right)-0.835 \ln \left(\frac{H}{4.0}\right)\right. \\
& \left.+\left(\frac{h}{0.6}\right)^{1.804}+0.067 \ln \left(\frac{b}{0.6}\right)-0.168\right] \\
I_{0}(0.2)= & 1000\left[0.053 \exp \left(\frac{\rho_{s}}{0.01}\right)+0.107\left(\frac{\rho}{0.01}\right)+0.021 \exp \left(\frac{f_{c}^{\prime}}{30}\right)+\left(\frac{H}{4.0}\right)^{-0.207}\right. \\
& \left.+1.203 \exp \left(\frac{h}{0.6}\right)-0.943 \ln \left(\frac{b}{0.6}\right)-2.686\right] \\
& \left.+2.639\left(\frac{h}{0.6}\right)+0.318 \ln \left(\frac{b}{0.6}\right)-2.271\right] \\
P_{0}(0.5) & =1000\left[0.143 \ln \left(\frac{\rho_{s}}{0.01}\right)+0.320 \ln \left(\frac{\rho}{0.01}\right)+0.063 \exp \left(\frac{f_{c}^{\prime}}{30}\right)+\left(\frac{H}{4.0}\right)^{-1.390}\right. \\
I_{0}(0.5) & =1000\left[0.837\left(\frac{\rho_{s}}{0.01}\right)+0.036\left(\frac{\rho}{0.01}\right)+0.235 \exp \left(\frac{f_{c}^{\prime}}{30}\right)+\left(\frac{H}{4.0}\right)^{-0.274}\right. \\
& \left.+2.271 \exp \left(\frac{h}{0.6}\right)-0.998 \ln \left(\frac{b}{0.6}\right)-5.286\right] \\
& \left.+2.439 \ln \left(\frac{h}{0.6}\right)+0.210 \ln \left(\frac{b}{0.6}\right)+1.563\right] \\
P_{0}(0.8) & =1000\left[0.062 \ln \left(\frac{\rho_{s}}{0.01}\right)+0.238\left(\frac{\rho}{0.01}\right)+0.291 \ln \left(\frac{f_{c}^{\prime}}{30}\right)-1.676 \ln \left(\frac{H}{4.0}\right)\right. \\
I_{0}(0.8)= & 1000\left[3.448\left(\frac{\rho_{s}}{0.01}\right)-0.254\left(\frac{\rho}{0.01}\right)+1.200\left(\frac{f_{c}^{\prime}}{30}\right)-0.521\left(\frac{H}{4.0}\right)\right. \\
& \left.+6.993\left(\frac{h}{0.6}\right)-2.759 \ln \left(\frac{b}{0.6}\right)-2.035\right]
\end{aligned}\right.
\end{aligned}
$$

In Eq. (11)-(13), $P_{0}(D)$ is in $\mathrm{kPa}, I_{0}(D)$ is in kPams, $f_{c}^{\prime}$ is in MPa, $H, b$ and $h$ are all in meters. The comparison of the numerical results of a particular RC column with the formulae predicted result is given 
in Table 13. It illustrates that Eq (11)- Eq (13) give a good prediction of both the pressure asymptotes and impulsive asymptotes.

It should be noted here that although Eqs. (11) - (13) are derived from the numerical simulation results with the reinforcement steel yield strength $500 \mathrm{MPa}$, a very common value used in the structure design, these equations can also be used for RC columns with reinforcement steel of different yield strength by using the equivalent steel area when calculating the longitudinal and transverse reinforcement ratio. The equivalent steel area can be derived as:

$$
A_{s e}=\frac{f_{y}}{500} A_{s}
$$

Where $A_{s e}$ is the equivalent steel area, $A_{s}$ is the real steel area, $f_{y}$ is the yield strength of the reinforcement steel in MPa.

Since the pressure asymptotes and impulsive asymptotes for the pressure-impulse curves with damage degree 0.2, 0.5 and 0.8 can be derived using Eq (11)- Eq (13), the pressure-impulse curves can be easily obtained from Eq.(10).

The procedure to use the proposed analytical formulae to generate the pressure-impulse diagram of a $\mathrm{RC}$ column is as follows:

(1) Calculate the longitudinal and transverse reinforcement ratio of the RC column;

(2) Calculate the pressure asymptotes and impulsive asymptotes of the pressure-impulse curves using Eq (11) - Eq (13) for $\mathrm{D}=0.2,0.5$ and 0.8 respectively;

(3) Calculate the three critical pressure-impulse curves that divide the low damage, medium damage, high damage and collapse using Eq. (10).

\subsection{Comparison with SDOF approach}

If the RC column is simplified as an equivalent elastic-perfect plastic SDOF model, the method proposed by Fallan and Louca [9] can also be used to generate pressure-impulse diagram for RC columns. The comparison between the proposed formulae with the SDOF approach is presented in this section. 
Consider a case study of a RC column C4 with the following configuration: $b=500 \mathrm{~mm}, h=500 \mathrm{~mm}$, $H=4000 \mathrm{~mm}, f_{c}{ }^{\prime}=40 \mathrm{MPa}, \rho=0.01, \rho_{\mathrm{s}}=0.01$. Using the above proposed procedure, the pressure-impulse diagram can be easily derived, as seen in Fig. 9. To verify the reliability of the pressure-impulse diagram in predicting the damage level of the column C4, three groups of blast loads with different peak pressure and impulse combinations are applied to the column. For each combination of peak pressure and impulse, the damage level of the column is measured directly from the pressure-impulse curves, and from the numerical simulation. The two results are compared in Table 14. As can be seen again, the column damage levels directly measured from the pressure-impulse curves agree well with the numerical simulation results.

Using the method proposed by Biggs [31], the continuous RC column is transformed to an equivalent elastic-perfect plastic SDOF system. The equivalent lumped mass of the SDOF system is $M=1059 \mathrm{~kg}$ and the equivalent structural stiffness $K=6.86 \times 10^{7} \mathrm{~N} / \mathrm{m}$. Using the Fallan and Louca's approach [9], the pressure-impulse diagrams based on the SDOF approach are derived and also plotted in Fig. 9.

It should be noted that the damage criterion of the SDOF approach proposed by Fallan and Louca [9] is based on the deflection of the SDOF system $y_{c}$, i.e., different values of $y_{c}$ corresponds to different damage degrees. As the SDOF approach is based on the assumption that the first mode of the structure is the dominant response mode, the critical values of $y_{c}$ are set to be the numerical mid-height deflection of the RC column. To eliminate uncertainties in estimating the critical deflection for comparison, the midheight deflection is obtained from numerical simulation. The critical values of $y_{c}$ for different damage levels are given in Table 15. The corresponding damage levels according to the proposed axial load carrying capacity are also given in the table.

From Fig. 9, one can notice that the pressure-impulse diagrams from the proposed method have much higher pressure levels in the quasi-static loading region in comparison with those predicted by the SDOF approach. This is probably because the material idealization and the negligence of strain rate effects in the SDOF approach underestimate the blast loading resistance capacity of the column. Similar observation has also been made by Lan and Crawford [10]. In the impulsive loading region, however, the pressureimpulse curves derived from the present method and the SDOF approach match reasonably well despite the same material idealization and strain rate effect negligence problem. This might attribute to the 
combination of overestimation of damage owing to material idealization and strain rate negligence and underestimation owing to inappropriate flexural deflection-based damage criterion in the impulsive loading region. A column is usually damaged owing to shear failure in the impulsive loading region. The flexural deflection based damage criterion used in the SDOF approach might underestimate damage level since shear deformation is usually much smaller than flexural deformation. Based on the above discussions and since the numerical model is verified against the field test data as presented above, it is believed that the pressure-impulse diagram generated by the proposed analytical formulae in this study is more accurate than those by the SDOF approach.

\section{Conclusions}

In this paper, a numerical method to analyse the RC column damage under blast loads is validated using published test data. During the validation process, the bond slip effect on the RC column response is also studied. The results show that when the bond slip between steel bar and concrete is considered, better prediction of the RC column response could be achieved.

A new damage criterion for RC columns is defined based on the residual axial load carrying capacity. Using this damage criterion, the pressure-impulse diagrams for several RC columns are derived from the numerical simulations. Based on the results of the derived pressure-impulse diagrams, an analytical equation for the pressure-impulse diagram for RC columns is proposed.

Parametric studies are also carried out to study the effect of column dimension, concrete strength, longitudinal and transverse reinforcement ratio on the pressure-impulse diagram of the RC column.

Based on the numerical results, analytical formulae to predict the pressure asymptotes and impulsive asymptotes for the pressure-impulse curves are derived. The comparison between the pressure-impulse curves established from the proposed analytical formulae and from numerical simulation show that they agree well with each other. A case study is carried out and the results are compared with those based on SDOF approach. It is shown that the proposed method gives better predictions of pressure-impulse diagrams of RC columns than the SDOF approach. 


\section{ACKNOWLEDGEMENT}

The authors would like to acknowledge the financial support from the Australian Research Council under grant number DP0774061, and National Natural Science Foundation of China under grant number 50528808 as a Cheung Kong Scholar of Ministry of Education of China for carrying out this research.

\section{References}

1. Jarrett D. F. Derivation of British explosives safety distances. Annuals of the New York Academy of Science 1968; 152: 18-35.

2. Mays G. C.,Smith P. D. Blast effects on buildings-design of buildings to optimize resistance to blast loading, Thomas Telford, London, 1995.

3. Krauthammer T. Blast mitigation technologies: developments and numerical considerations for behaviour assessment and Design, Proceeding of Int. Conf. on Structures Under Shock and Impact, SUSI, 1998.

4. Merrifield R. Simplified calculations of blast induced injuries and damage. Rep. No. 37, Health and Safety Executive Specialist Inspector, 1993.

5. Smith P.,Hetherington J. Blast and ballistic loading of structures, Butterworth-Heinemann LtdGreat Britain: Butterworth-Heinemann Ltd, London, 1994.

6. Baker W. E., Cox P. A., Westine P. S., Kulesz J. J.,Strehlow R. A. Explosion hazards and evaluation, Elsevier, London, 1983.

7. Li Q. M.,Meng H. Pressure-impulse diagram for blast loads based on dimensional analysis and singledegree-of-freedom model. Journal of Engineering Mechanics 2002; 128: 87-92.

8. Li Q. M.,Meng H. Pulse loading shape effects on pressure-impulse diagram of an elastic-plastic, singledegree-of-freedom structural model. International Journal of Mechanical Sciences 2002; 44: 1985-98.

9. Fallah A. S.,Louca L. A. Pressure-impulse diagrams for elastic-plastic-hardening and softening singledegree-of-freedom models subjected to blast loading. International Journal of Impact Engineering 2007; 34: 823-42.

10. Lan S. R.,Crawford J. C. Evaluation of the blast resistance of metal deck proofs, Proceeding of $5^{\text {th }}$ Asia-Pacific Conference on Shock \& Impact Loads on Structures, Changsha, Hunan, China. 2003.

11. Ma G. W., Shi H. J.,Shu D. W. P-I diagram method for combined failure modes of rigid-plastic beams. International Journal of Impact Engineering 2007; 34: 1081-94.

12. Schneider P. Predicting damage of slender cylindrical steel shells under pressure wave load. Journal of Loss Prevention in the Process Industries 1998; 11: 223-8.

13. Wesevich J. W.,Oswald C. J. Empirical Based Concrete Masonry Pressure-Impulse Diagrams for Varying Degrees of Damage, Structures 2005, New York 2005.

14. Karthaus W.,Leussink J. W. Dynamic Loading: More than Just a Dynamic Load Factor, Proceeding of the First International Symposium on the Interaction of Non-Nuclear Munitions with Structures Colorado. 1983.

15. Wu C.,Hao H. Modelling of simultaneous ground shock and air blast pressure on nearby structures from surface explosions. International Journal of Impacting Engineering 2005; 31: 699-717. 
16. Technical Manual (TM5-1300). To resist the effect of accidental explosions, Department of the Army, Navy and the Air force, Washington, DC, 1990.

17. LS-DYNA. Keyword User's Manual, Livermore Software Technology Coporation, Livermore, California, 2006.

18. Malvar L.,Simons D. Concrete Material Modeling in Explicit Computations, Proceeding of Workshop on Recent Advances in Computational Strucrtural Dynamics and High Performance Computing, USAE Waterways Experiment Station, Vicksburg, MS. 1996.

19. Malvar L., Crawford J.,Morrill K. K\&C concrete material model, release III: automated generation of material model input. Report: TR-99-24, Karagozian \& Case Structural Engineers, 2000.

20. Hansson H. 2D and 3D Simulations of Concrete Penetration using the RHT Material Model. User report: FOI-R-0922-SE, Swedish Defence Research Agency Weapons and Protection Tumba, 2003.

21. Malvar L. J.,Ross C. A. Review of strain rate effects for concrete in tension. ACI Materials Journal 1999; 96: 614-16.

22. Bischoff P. H.,Perry S. H. Compressive Behavior of Concrete at High Strain Rate. Materials and Strucutres 1991; 24: 425-50.

23. Malvar L. Review of Static and Dynamic Properties of Steel Reinforcing Bars ACI Materials Journal 1998; 95: 609-16.

24. Luccioni B. M., Lopez D. E.,Danesi R. F. Bond-slip in reinforced concrete elements. Journal of Structural Engineering 2005; 131: 1690-98.

25. Spacone E.,Limkatanyu S. Responses of reinforced concrete members including bond-slip effects. ACI Structural Journal 2000; 97: 831-9.

26. Weatherby J. H. Investigation of Bond Slip between Concrete and Steel Reinforcement under Dyanmic Loading Conditions The Department of Civil and Environmental Engineering, Mississippi State University. 2003.

27. Woodson S. C.,Baylot J. T. Structural Collapse: Quarter-Scale Model EXperiments. Technical Report SL-99-8, US Army Corps of Engineers Engineer Research and Development Center, 1999.

28. Woodson S. C.,Baylot J. T. Quarter-Scale Building/Column Experiments, Proceeding of Advanced Technology in Structural Engineering, Philadelphia, Pennsylvania, USA. 2000.

29. AUTODYN. Theory manual, Century Dynamics, 2006.

30. MacGregor J. G. G. Reinforced Concrete: Mechanics and Design., Prentice Hall,Professional Technical Reference, 1996.

31. Biggs J. M. Introduction to Structure Dynamics, McGraw-Hill Book Company, New York, 1964. 


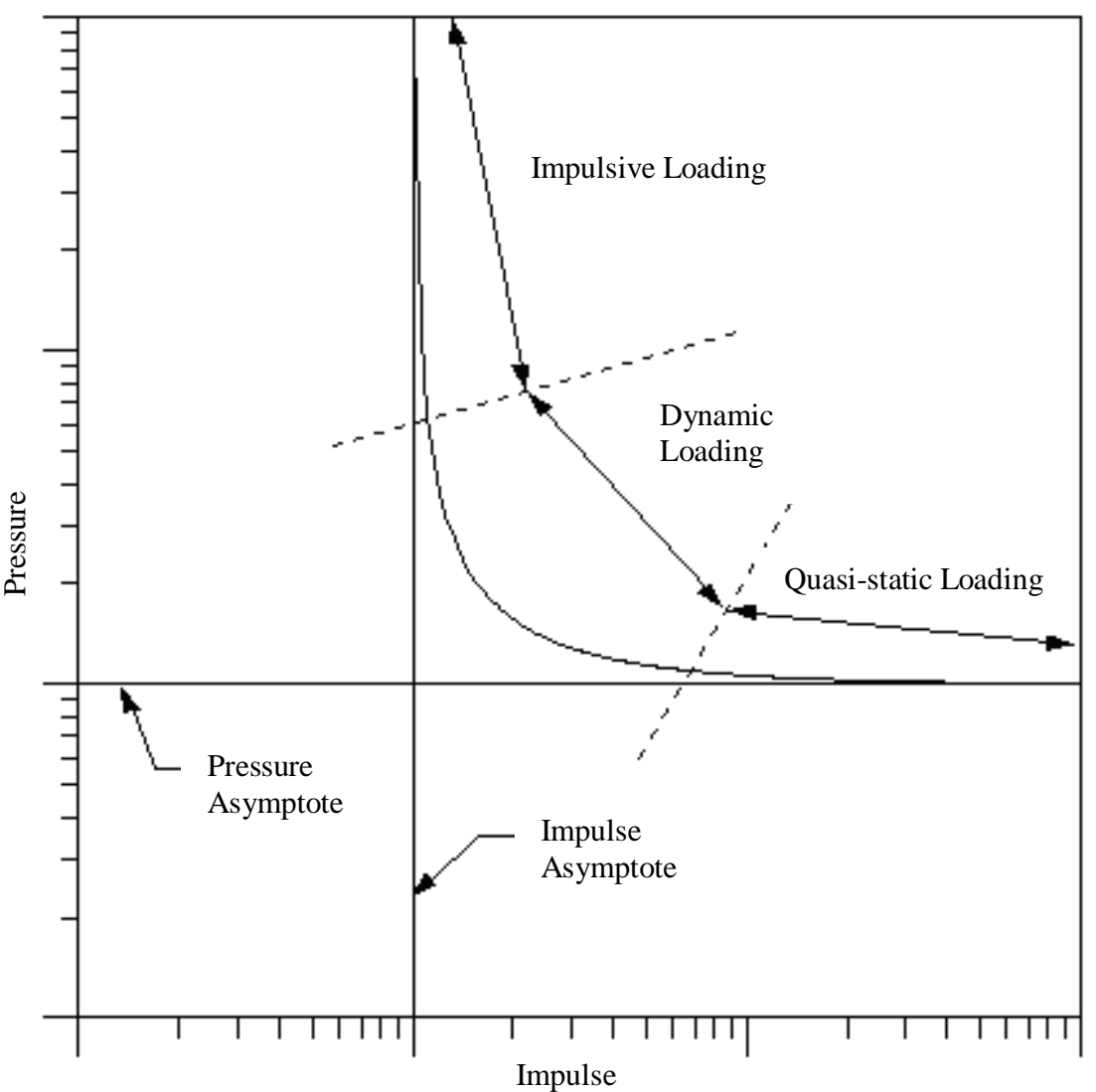

Fig. 1 Sketch of a typical pressure impulse curve 
Blast face

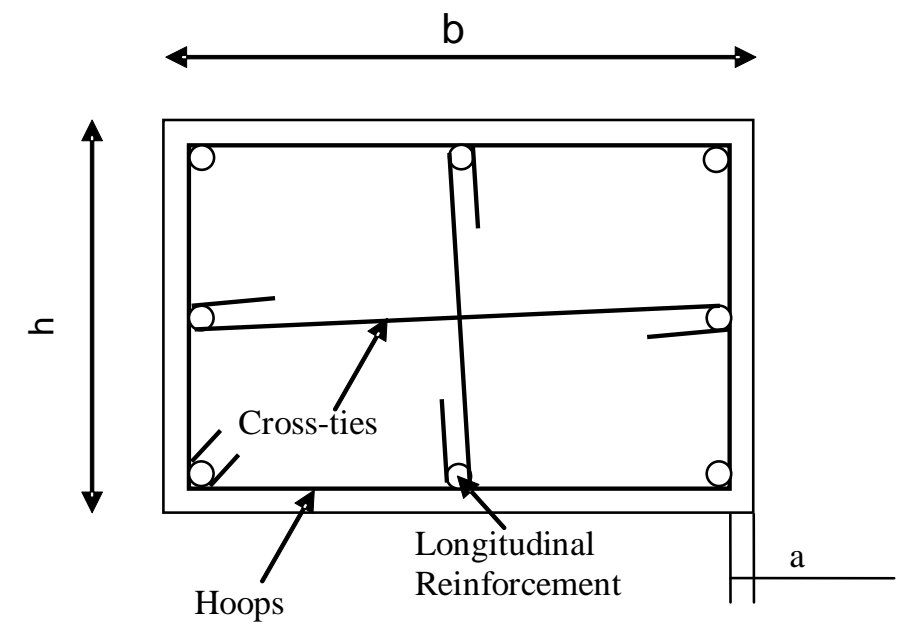

(a)
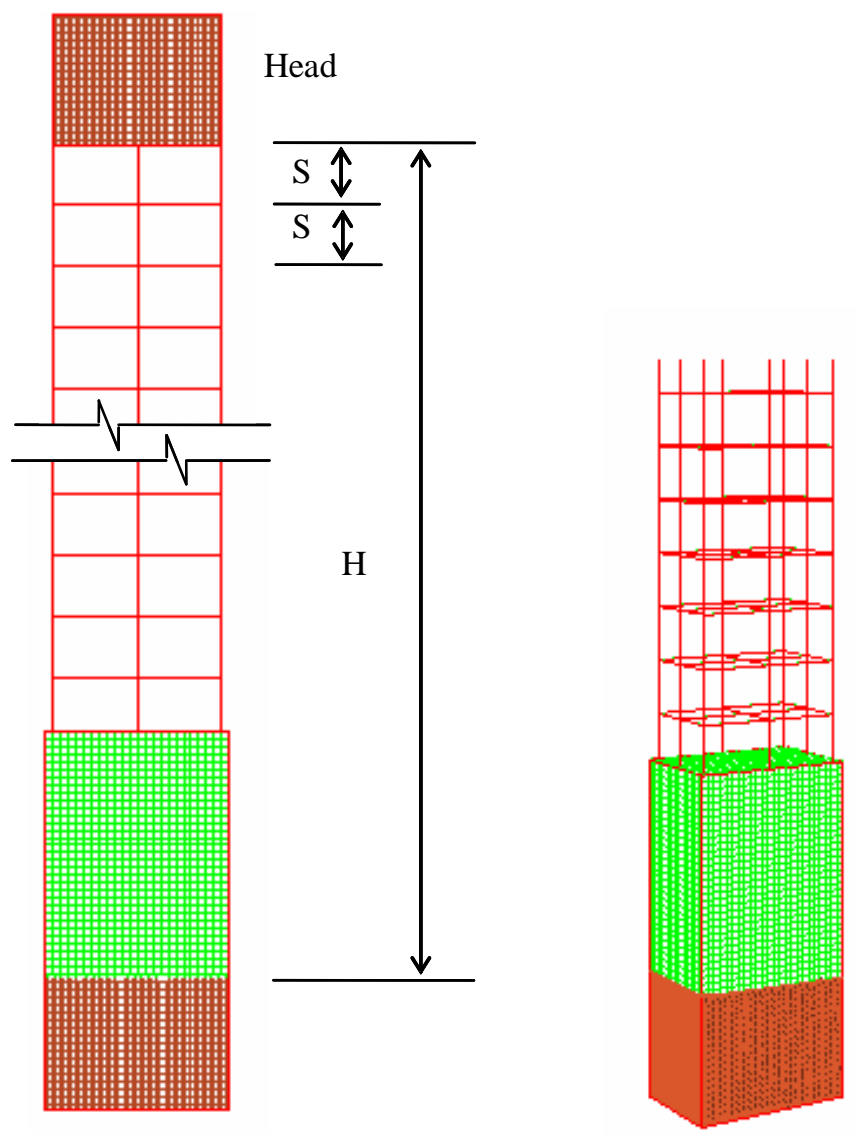

Rebar and ties

Concrete

Footing

(b)

Fig. 2 Column details 


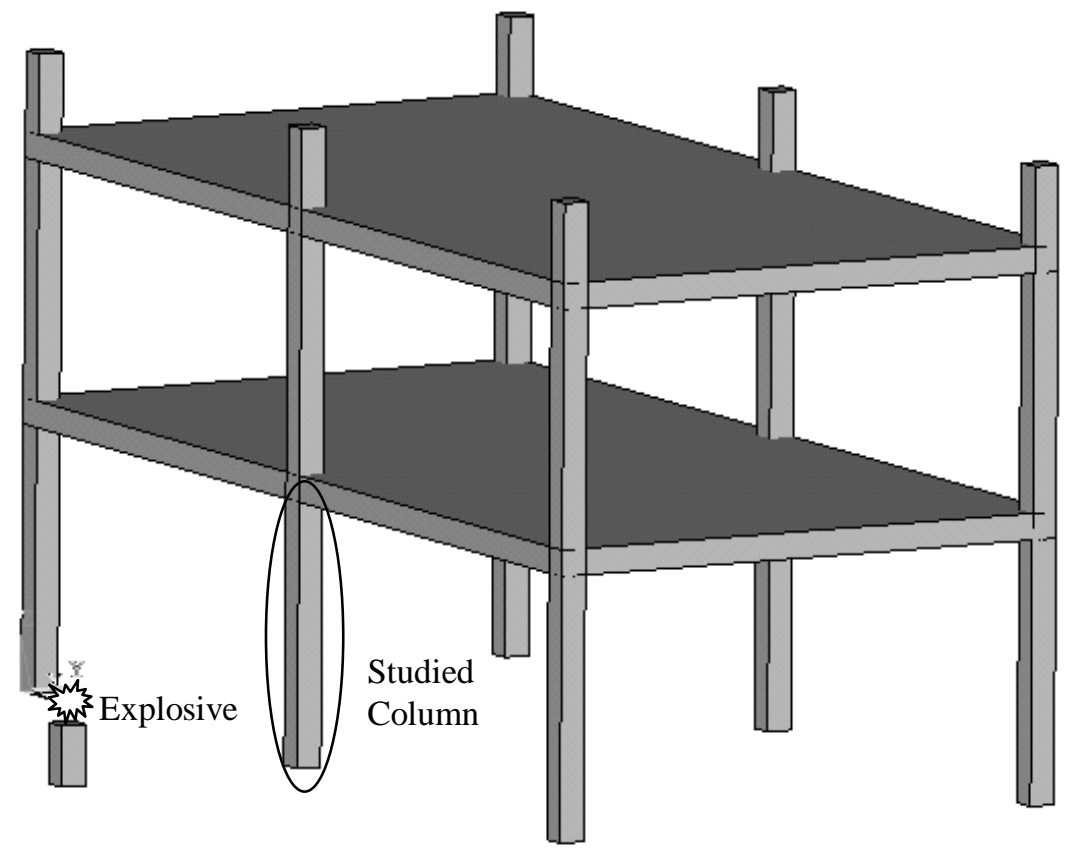

(a)

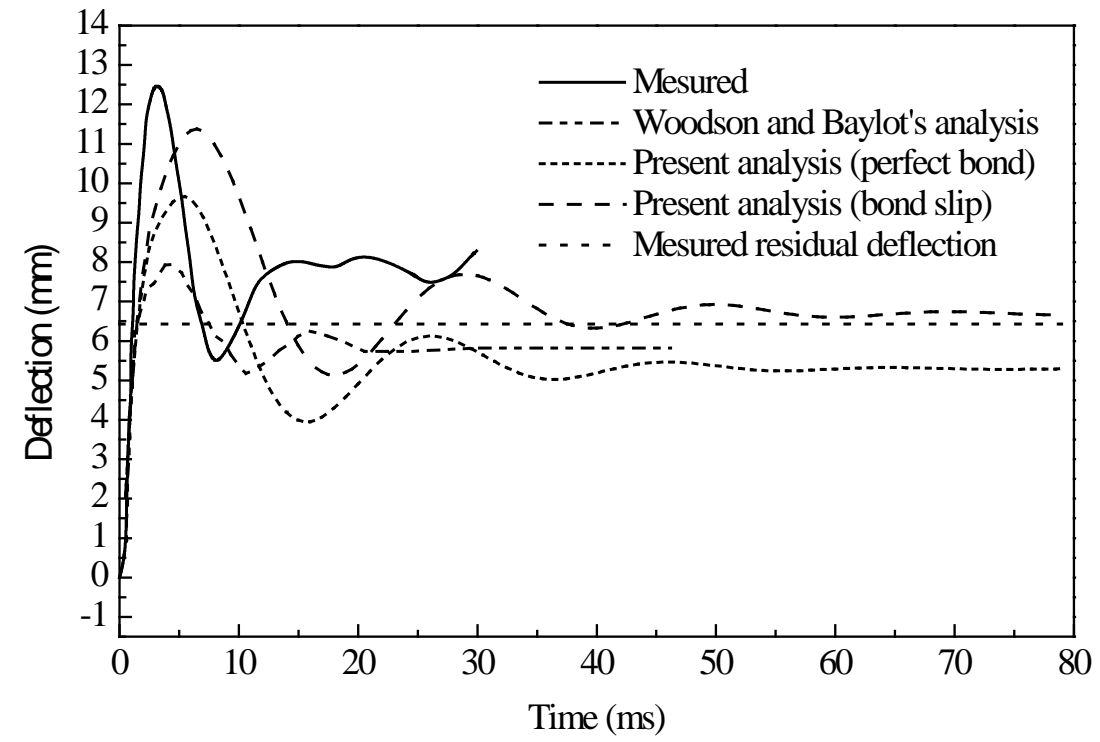

(b)

Fig. 3 Numerical model validation (a) Sketch of the field test used to calibrate the numerical model; (b) Comparison of the middle height deflection 


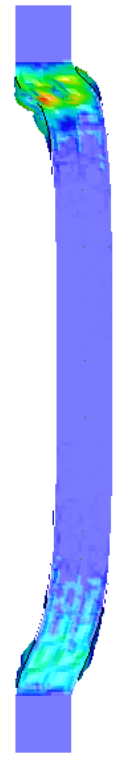

(a)
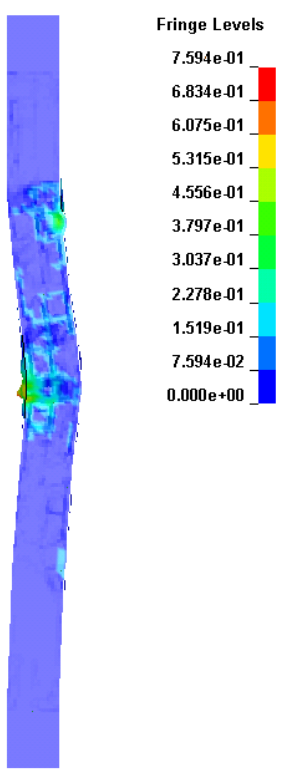

(b)

$0.000 \mathrm{e}+00$

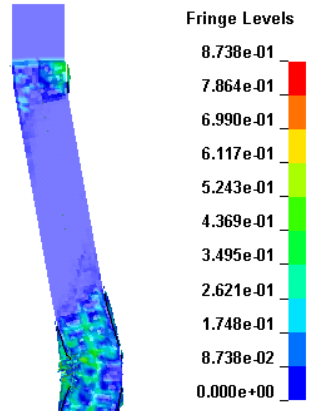

s.

Fig. 4 Damage modes of RC column C1 under blast loads (a) Shear damage ( $\mathrm{P}=25000 \mathrm{kPa}, \mathrm{I}=2400$ $\mathrm{kPa} \cdot \mathrm{ms})(\mathrm{b})$ Flexural damage $(\mathrm{P}=700 \mathrm{kPa}, \mathrm{I}=50000 \mathrm{kPa} \cdot \mathrm{ms})$ (c) Combined shear and flexural damage $(\mathrm{P}=5000 \mathrm{kPa}, \mathrm{I}=5000 \mathrm{kPa} \cdot \mathrm{ms})$ 


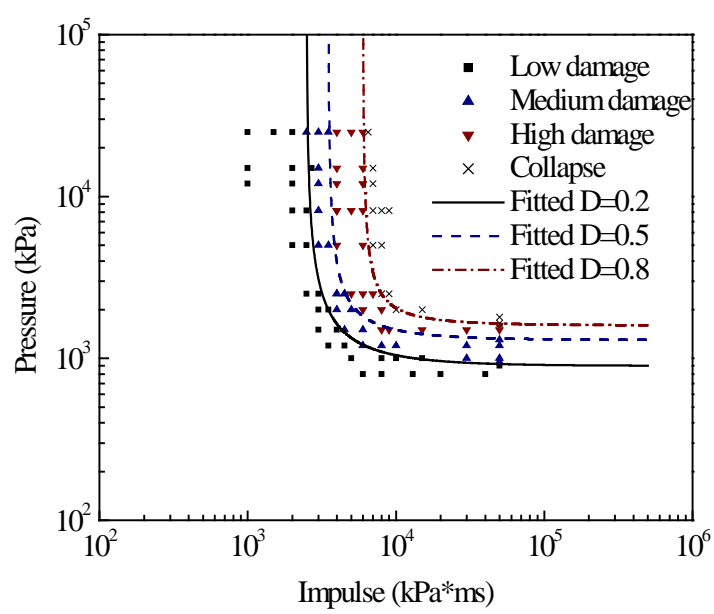

(a)

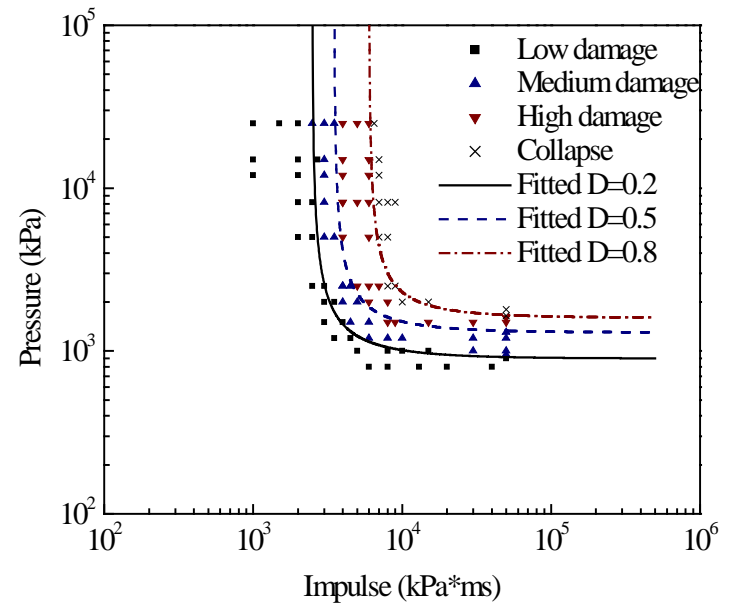

(b)

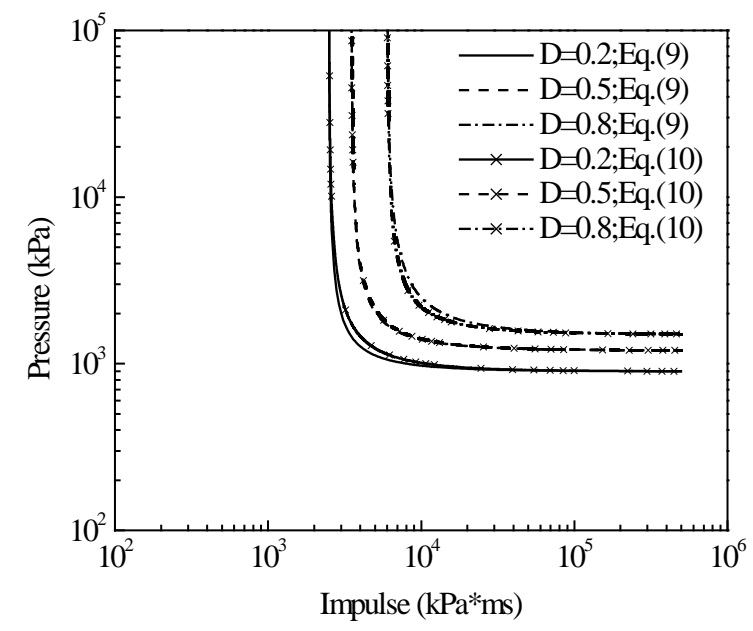

(c)

Fig. 5 Pressure-impulse diagram for RC column C2 (a) numerical data and fitted curves; (b) fitted curves according to Eq. (10); (c) comparison of the curves in (a) and (b) 


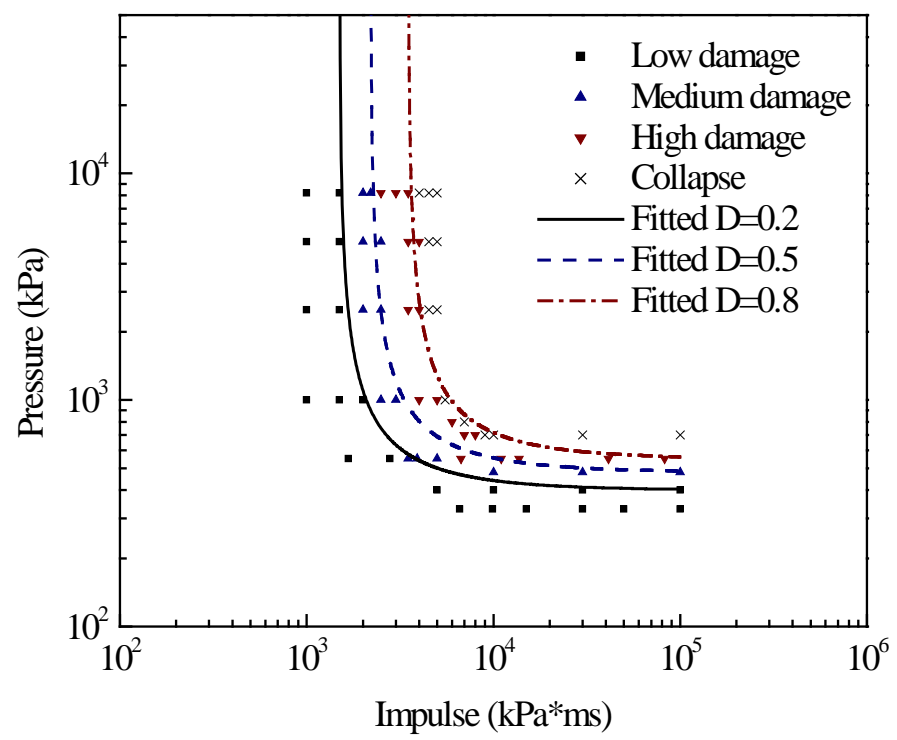

Fig. 6 Pressure-impulse diagrams for RC column C3 fitted according to Eq. (10) 


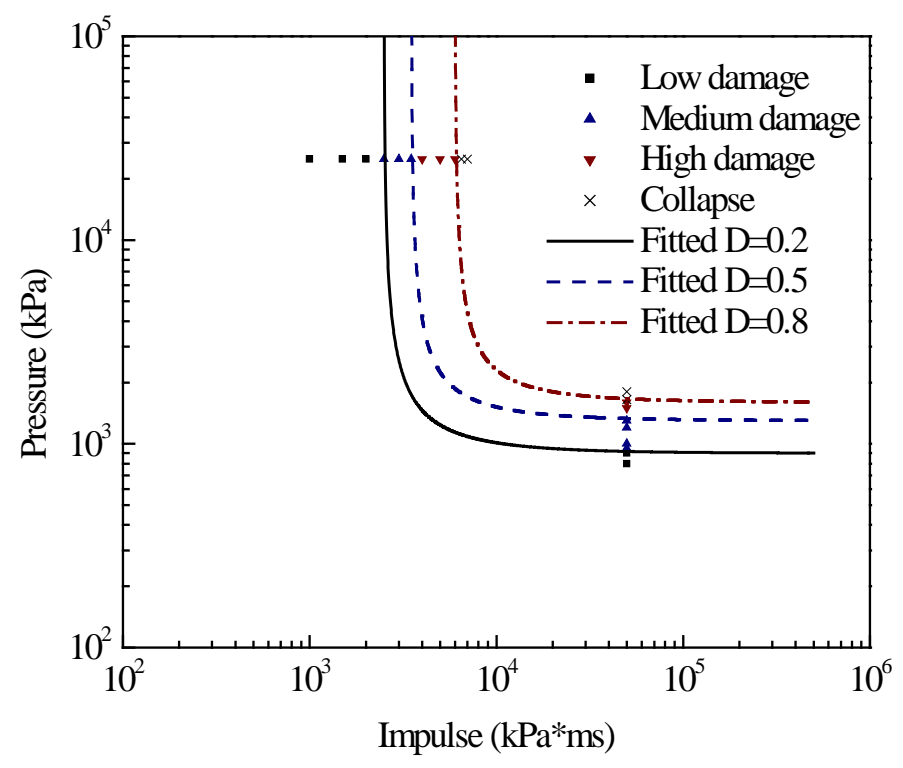

Fig. 7 Pressure-impulse diagram for RC column C2 obtained using the simplified numerical method 


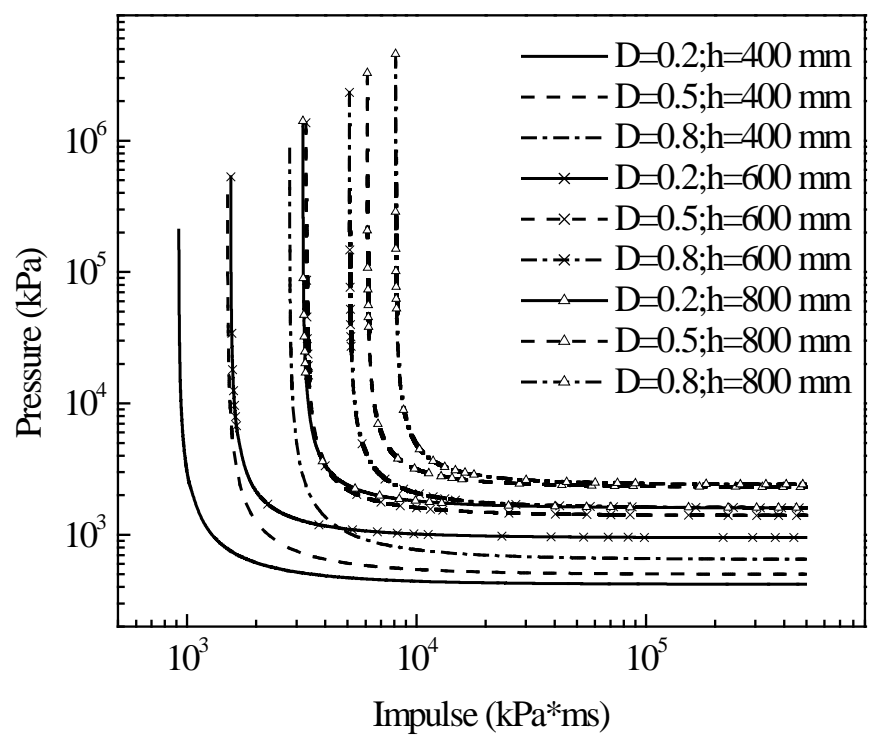

Fig. 8 comparison of pressure-impulse curves for RC columns with different depth ( $b=600 \mathrm{~mm}, H=4600$ $\mathrm{mm}, f_{c}^{\prime}=40 \mathrm{MPa}, \rho=0.01 \rho_{\mathrm{s}}=0.006$ ) 


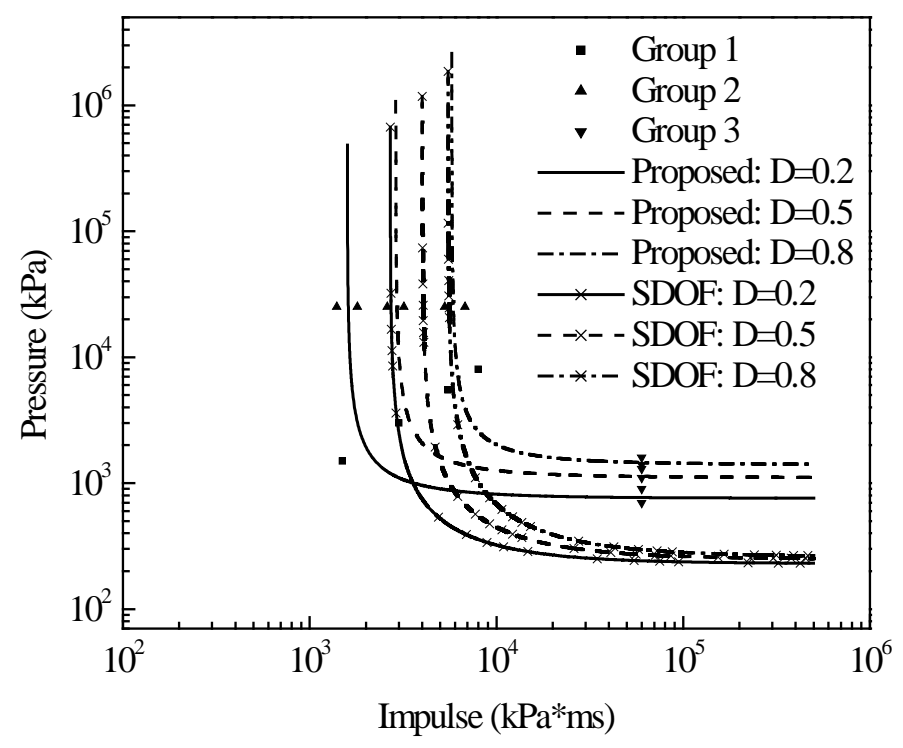

Fig. 9 Pressure-impulse diagrams for RC column C4 obtained from the proposed formulae and SDOF approach (column configuration: $b=500 \mathrm{~mm}, h=500 \mathrm{~mm}, H=4000 \mathrm{~mm}, f_{c}^{\prime}=40 \mathrm{MPa}, \rho=0.01 \rho_{\mathrm{s}}=0.01$ ) 
Table 1 Material properties of the steel

\begin{tabular}{llllll}
\hline $\begin{array}{l}\text { Density } \\
\mathrm{g} / \mathrm{mm}^{3}\end{array}$ & $\begin{array}{l}\text { Young's modulus } \\
\mathrm{MPa}\end{array}$ & Poisson ratio & $\begin{array}{l}\text { Yield stress } \\
\mathrm{MPa}\end{array}$ & $\begin{array}{l}\text { Tangent modulus } \\
\mathrm{MPa}\end{array}$ & Fracture strain \\
\hline 0.0078 & 200000 & 0.3 & 550 & 1600 & $12 \%$ \\
\hline
\end{tabular}

Table 2 Configuration of the analysed quarter-scale RC column ${ }^{*}$

\begin{tabular}{l|l|lllll}
\hline $\begin{array}{l}\text { Column } \\
\text { No. }\end{array}$ & $\begin{array}{l}\text { Column } \\
\text { width } \\
\text { mm }\end{array}$ & $\begin{array}{l}\text { Column } \\
\text { depth } \\
\text { mm }\end{array}$ & $\begin{array}{l}\text { Column } \\
\text { height } \\
\text { mm }\end{array}$ & $\begin{array}{l}\text { Cross } \\
\text { tie/Hoop }\end{array}$ & $\begin{array}{l}\text { Longitudinal } \\
\text { reinforcement }\end{array}$ & $\begin{array}{l}\text { Cover depth } \\
\text { mm }\end{array}$ \\
\hline C1 & 85 & 85 & 900 & D1.6@100 & 8D3.2 & 8.5 \\
\hline C2 & 400 & 600 & 4600 & D10@200 & 8D20 & 25 \\
\hline C3 & 600 & 400 & 4600 & D10@200 & 8D20 & 25 \\
\hline
\end{tabular}

Table 3 Material properties*

\begin{tabular}{|c|c|c|c|c|c|c|}
\hline $\begin{array}{l}\text { Unconfined } \\
\text { Concrete } \\
\text { strength } \\
\mathrm{MPa}\end{array}$ & $\begin{array}{l}\text { Yield stress } \\
\text { of } \\
\text { longitudinal } \\
\text { steel } \mathrm{MPa}\end{array}$ & $\begin{array}{l}\text { Ultimate } \\
\text { stress of } \\
\text { longitudinal } \\
\text { steel MPa }\end{array}$ & $\begin{array}{l}\text { Fracture } \\
\text { strain of } \\
\text { longitudinal } \\
\text { steel }\end{array}$ & $\begin{array}{l}\text { Yield stress } \\
\text { of } \\
\text { cross tie/ } \\
\text { hoop } \mathrm{MPa}\end{array}$ & $\begin{array}{l}\text { Ultimate } \\
\text { stress of } \\
\text { cross tie/ } \\
\text { hoop } \mathrm{MPa}\end{array}$ & $\begin{array}{l}\text { Fracture } \\
\text { strain of } \\
\text { cross } \\
\text { tie/hoop }\end{array}$ \\
\hline 42 & 450 & 510 & $18 \%$ & 400 & 610 & $18 \%$ \\
\hline
\end{tabular}

Table 4 Blast load configuration*

\begin{tabular}{lllll}
\hline $\begin{array}{l}\text { Charge weight } \\
\text { (C-4) } \mathrm{g}\end{array}$ & $\begin{array}{l}\text { Equivalent weight } \\
\text { of TNT charge } \mathrm{g}\end{array}$ & $\begin{array}{l}\text { Stand-off distance } \\
\mathrm{mm}\end{array}$ & $\begin{array}{l}\text { charge height } \\
\mathrm{mm}\end{array}$ & $\begin{array}{l}\text { Initial Axial stress } \\
\mathrm{MPa}\end{array}$ \\
\hline 7100 & 8000 & 1070 & 229 & 2.1 \\
\hline
\end{tabular}

* For details, see [27, 28].

Table 5 Value of the parameters in Eq. (9)

\begin{tabular}{lllll}
\hline $\mathrm{D}$ & $\mathrm{P}_{0}(\mathrm{kPa})$ & $\mathrm{I}_{0}(\mathrm{kPa} \bullet \mathrm{ms})$ & $\mathrm{A}$ & $\beta$ \\
\hline 0.2 & 900 & 2500 & 11.5 & 1.45 \\
0.5 & 1200 & 3500 & 12 & 1.49 \\
0.8 & 1500 & 6000 & 12.5 & 1.54 \\
\hline
\end{tabular}

Table 6 Range of the parameters studied

\begin{tabular}{|c|c|c|c|c|c|}
\hline $\begin{array}{l}\text { Width } \\
b \\
\mathrm{~mm}\end{array}$ & $\begin{array}{l}\text { Depth } \\
h \\
\mathrm{Mm}\end{array}$ & $\begin{array}{l}\text { Height } \\
H \\
\mathrm{~mm}\end{array}$ & $\begin{array}{l}\text { Concrete strength } \\
f c \\
\mathrm{MPa}\end{array}$ & $\begin{array}{l}\text { Longitudinal } \\
\text { reinforcement } \\
\text { ratio } \rho\end{array}$ & $\begin{array}{l}\text { Transverse } \\
\text { reinforcement } \\
\text { ratio } \rho_{s}\end{array}$ \\
\hline 400 & 400 & 3600 & 30 & 0.01 & 0.006 \\
\hline 600 & 600 & 4600 & 40 & 0.02 & 0.016 \\
\hline 800 & 800 & 5400 & 50 & 0.03 & 0.032 \\
\hline
\end{tabular}

Table 7 Effect of column depth on pressure and impulsive asymptotes

\begin{tabular}{lllllll}
\hline Depth & \multicolumn{3}{c}{$\mathrm{D}=0.2$} & \multicolumn{2}{c}{$\mathrm{D}=0.5$} & $\mathrm{D}=0.8$ \\
\cline { 2 - 7 } $\mathrm{mm}$ & $\mathrm{P}_{0}$ & $\mathrm{I}_{0}$ & $\mathrm{P}_{0}$ & $\mathrm{I}_{0}$ & $\mathrm{P}_{0}$ & $\mathrm{I}_{0}$ \\
& $\mathrm{kPa}$ & $\mathrm{kPa} \cdot \mathrm{ms}$ & $\mathrm{kPa}$ & $\mathrm{kPa} \cdot \mathrm{ms}$ & $\mathrm{kPa}$ & $\mathrm{kPa} \cdot \mathrm{ms}$ \\
\hline 400 & 420 & 920 & 500 & 1500 & 650 & 2800 \\
600 & 950 & 1550 & 1400 & 3300 & 1600 & 5100 \\
800 & 1600 & 3200 & 2300 & 6100 & 2400 & 8100 \\
\hline
\end{tabular}


Table 8 Effect of column height on pressure and impulsive asymptotes

\begin{tabular}{lllllll}
\hline Height & \multicolumn{3}{c}{$\mathrm{D}=0.2$} & \multicolumn{2}{c}{$\mathrm{D}=0.5$} & $\mathrm{D}=0.8$ \\
\cline { 2 - 7 } $\mathrm{mm}$ & $\mathrm{P}_{0}$ & $\mathrm{I}_{0}$ & $\mathrm{P}_{0}$ & $\mathrm{I}_{0}$ & $\mathrm{P}_{0}$ & $\mathrm{I}_{0}$ \\
& $\mathrm{kPa}$ & $\mathrm{kPa} \cdot \mathrm{ms}$ & $\mathrm{kPa}$ & $\mathrm{kPa} \cdot \mathrm{ms}$ & $\mathrm{kPa}$ & $\mathrm{kPa} \cdot \mathrm{ms}$ \\
\hline 3600 & 650 & 1000 & 950 & 1700 & 1200 & 2800 \\
4600 & 440 & 920 & 580 & 1750 & 730 & 2700 \\
5400 & 310 & 900 & 430 & 1650 & 530 & 2600 \\
\hline
\end{tabular}

Table 9 Effect of column width on pressure and impulsive asymptotes

\begin{tabular}{lllllll}
\hline Width & \multicolumn{3}{c}{$\mathrm{D}=0.2$} & \multicolumn{2}{c}{$\mathrm{D}=0.5$} & $\mathrm{D}=0.8$ \\
\cline { 2 - 7 } $\mathrm{mm}$ & $\mathrm{P}_{0}$ & $\mathrm{I}_{0}$ & $\mathrm{P}_{0}$ & $\mathrm{I}_{0}$ & $\mathrm{P}_{0}$ & $\mathrm{I}_{0}$ \\
& $\mathrm{kPa}$ & $\mathrm{kPa} \cdot \mathrm{ms}$ & $\mathrm{kPa} \cdot \mathrm{ms}$ & $\mathrm{kPa} \cdot \mathrm{ms}$ & $\mathrm{kPa}$ & $\mathrm{kPa} \cdot \mathrm{ms}$ \\
\hline 400 & 900 & 2500 & 1200 & 3500 & 1500 & 6000 \\
600 & 950 & 1550 & 1400 & 3300 & 1600 & 5100 \\
800 & 950 & 1700 & 1450 & 2900 & 1650 & 4850 \\
\hline
\end{tabular}

Table 10 Effect of concrete strength on pressure and impulsive asymptotes

\begin{tabular}{|c|c|c|c|c|c|c|}
\hline \multirow{2}{*}{$\begin{array}{l}\mathrm{f}_{\mathrm{c}}^{\prime} \\
\mathrm{MPa}\end{array}$} & \multicolumn{2}{|c|}{$\mathrm{D}=0.2$} & \multicolumn{2}{|c|}{$\mathrm{D}=0.5$} & \multicolumn{2}{|c|}{$\mathrm{D}=0.8$} \\
\hline & $\begin{array}{l}\mathrm{P}_{0} \\
\mathrm{kPa}\end{array}$ & $\begin{array}{l}\mathrm{I}_{0} \\
\mathrm{kPa} \cdot \mathrm{ms}\end{array}$ & $\begin{array}{l}\mathrm{P}_{0} \\
\mathrm{kPa}\end{array}$ & $\begin{array}{l}\mathrm{I}_{0} \\
\mathrm{kPa} \cdot \mathrm{ms}\end{array}$ & $\begin{array}{l}\mathrm{P}_{0} \\
\mathrm{kPa}\end{array}$ & $\begin{array}{l}\mathrm{I}_{0} \\
\mathrm{kPa} \cdot \mathrm{ms}\end{array}$ \\
\hline 30 & 360 & 900 & 450 & 1300 & 550 & 2300 \\
\hline 40 & 420 & 920 & 500 & 1500 & 650 & 2800 \\
\hline 50 & 450 & 900 & 600 & 1900 & 700 & 3100 \\
\hline
\end{tabular}

Table 11 Effect of amount of transverse reinforcement on pressure and impulsive asymptotes

\begin{tabular}{|c|c|c|c|c|c|c|}
\hline \multirow{2}{*}{$\begin{array}{l}\text { Transverse } \\
\text { reinforcement } \\
\text { ratio }\end{array}$} & \multicolumn{2}{|c|}{$\mathrm{D}=0.2$} & \multicolumn{2}{|c|}{$\mathrm{D}=0.5$} & \multicolumn{2}{|c|}{$\mathrm{D}=0.8$} \\
\hline & $\begin{array}{l}\mathrm{P}_{0} \\
\mathrm{kPa}\end{array}$ & $\begin{array}{l}\mathrm{I}_{0} \\
\mathrm{kPa} \bullet \mathrm{ms}\end{array}$ & $\begin{array}{l}\mathrm{P}_{0} \\
\mathrm{kPa}\end{array}$ & $\begin{array}{l}\mathrm{I}_{0} \\
\mathrm{kPa} \cdot \mathrm{ms}\end{array}$ & $\begin{array}{l}\mathrm{P}_{0} \\
\mathrm{kPa}\end{array}$ & $\begin{array}{l}\mathrm{I}_{0} \\
\mathrm{kPa} \cdot \mathrm{ms}\end{array}$ \\
\hline 0.006 & 560 & 2100 & 690 & 3800 & 720 & 12000 \\
\hline 0.016 & 420 & 1200 & 620 & 2300 & 700 & 5500 \\
\hline 0.032 & 420 & 920 & 500 & 1500 & 650 & 2800 \\
\hline
\end{tabular}

Table 12 Effect of amount of longitudinal reinforcement on pressure and impulsive asymptotes

\begin{tabular}{|c|c|c|c|c|c|c|}
\hline \multirow{2}{*}{$\begin{array}{l}\text { Longitudinal } \\
\text { reinforcement } \\
\text { ratio }\end{array}$} & \multicolumn{2}{|c|}{$\mathrm{D}=0.2$} & \multicolumn{2}{|c|}{$\mathrm{D}=0.5$} & \multicolumn{2}{|c|}{$\mathrm{D}=0.8$} \\
\hline & $\begin{array}{l}\mathrm{P}_{0} \\
\mathrm{kPa}\end{array}$ & $\begin{array}{l}\mathrm{I}_{0} \\
\mathrm{kPa} \bullet \mathrm{ms}\end{array}$ & $\begin{array}{l}\mathrm{P}_{0} \\
\mathrm{kPa}\end{array}$ & $\begin{array}{l}\mathrm{I}_{0} \\
\mathrm{kPa} \cdot \mathrm{ms}\end{array}$ & $\begin{array}{l}\mathrm{P}_{0} \\
\mathrm{kPa}\end{array}$ & $\begin{array}{l}\mathrm{I}_{0} \\
\mathrm{kPa} \cdot \mathrm{ms}\end{array}$ \\
\hline 0.01 & 420 & 1200 & 620 & 2300 & 700 & 5500 \\
\hline 0.02 & 500 & 1200 & 850 & 2300 & 950 & 5500 \\
\hline 0.03 & 570 & 1300 & 1000 & 2350 & 1150 & 5500 \\
\hline
\end{tabular}

Table 13 Comparison of pressure and impulsive asymptotes obtained from proposed formulae and numerical results*

\begin{tabular}{llllcll}
\hline & \multicolumn{2}{c}{$\mathrm{D}=0.2$} & & $\mathrm{D}=0.5$ & & $\mathrm{D}=0.8$ \\
\cline { 2 - 7 } & $\mathrm{P}_{0}$ & $\mathrm{I}_{0}$ & $\mathrm{P}_{0}$ & $\mathrm{I}_{0}$ & $\mathrm{P}_{0}$ & $\mathrm{I}_{0}$ \\
& $\mathrm{kPa}$ & $\mathrm{kPa} \cdot \mathrm{ms}$ & $\mathrm{kPa}$ & $\mathrm{kPa} \cdot \mathrm{ms}$ & $\mathrm{kPa}$ & $\mathrm{kPa} \cdot \mathrm{ms}$ \\
\hline Numerical results & 420 & 920 & 500 & 1500 & 650 & 2800 \\
Formulae estimated & 407 & 912 & 478 & 1529 & 630 & 2684 \\
Error & $-3.1 \%$ & $-0.9 \%$ & $-4.4 \%$ & $1.9 \%$ & $-3.1 \%$ & $-4.1 \%$ \\
\hline
\end{tabular}

* The RC column: $b=600 \mathrm{~mm}, h=400 \mathrm{~mm}, H=4600 \mathrm{~mm}, f_{c}^{\prime}=40 \mathrm{MPa}, \rho=0.01 \rho_{\mathrm{s}}=0.006$ 
Table 14 Comparison of the proposed formulae predicted damage level and numerically obtained damage degree of column C4

\begin{tabular}{|c|c|c|c|}
\hline \multicolumn{2}{|c|}{ Blast load } & \multirow{2}{*}{$\begin{array}{l}\text { Damage level predicted } \\
\text { by formulae generated } \\
\text { pressure-impulse diagram }\end{array}$} & \multirow{2}{*}{$\begin{array}{l}\text { Degrees of damage obtained } \\
\text { from numerical analysis } \\
\text { D }\end{array}$} \\
\hline $\begin{array}{l}\text { Peak pressure } \\
\mathrm{kPa}\end{array}$ & $\begin{array}{l}\text { Impulse } \\
\mathrm{kPa} \cdot \mathrm{ms}\end{array}$ & & \\
\hline \multicolumn{4}{|l|}{ Group 1} \\
\hline 1500 & 1500 & 1: $\mathrm{D}=(0 \sim 0.2)$ & 0.02 \\
\hline 3000 & 3000 & $2: \mathrm{D}=(0.2 \sim 0.5)$ & 0.27 \\
\hline 5500 & 5500 & 3: $\mathrm{D}=(0.5 \sim 0.8)$ & 0.74 \\
\hline 7500 & 7500 & 4: $\mathrm{D}=(0.8 \sim 1)$ & 0.78 \\
\hline \multicolumn{4}{|l|}{ Group 2} \\
\hline 1400 & 25000 & 1 & 0.17 \\
\hline 1800 & 25000 & 2 & 0.22 \\
\hline 2600 & 25000 & 2 & 0.37 \\
\hline 3200 & 25000 & 3 & 0.49 \\
\hline 5300 & 25000 & 3 & 0.77 \\
\hline 6800 & 25000 & 4 & Collapse \\
\hline \multicolumn{4}{|l|}{ Group 3} \\
\hline 60000 & 700 & 1 & 0.01 \\
\hline 60000 & 900 & 2 & 0.17 \\
\hline 60000 & 1100 & 2 & 0.28 \\
\hline 60000 & 1300 & 3 & 0.47 \\
\hline 60000 & 1400 & 3 & 0.68 \\
\hline 60000 & 1600 & 4 & Collapse \\
\hline
\end{tabular}

Table 15 Comparison of the two damage criterions

\begin{tabular}{lll}
\hline Damage level & $\begin{array}{l}\text { Damage criterion for the SDOF } \\
\text { approach }\end{array}$ & $\begin{array}{l}\text { Damage criterion for the } \\
\text { proposed method }\end{array}$ \\
\hline Low damage & $y_{c}<20 \mathrm{~mm}$ & $\mathrm{D}<0.2$ \\
Medium damage & $20 \mathrm{~mm}<y_{c}<40 \mathrm{~mm}$ & $0.2<\mathrm{D}<0.5$ \\
High damage & $40 \mathrm{~mm}<c_{c}<80 \mathrm{~mm}$ & $0.5<\mathrm{D}<0.8$ \\
Collapse & $y_{c}>80 \mathrm{~mm}$ & $\mathrm{D}>0.8$ \\
\hline
\end{tabular}

